\title{
Merchant or Two-Sided Platform?
}

\author{
ANDREI HAGIU * \\ Strategy Unit, Harvard Business School
}

\begin{abstract}
This paper provides a first pass at comparing two polar strategies for market intermediation: "merchant" mode - buying from sellers and reselling to buyers - and "two-sided platform" mode enabling affiliated sellers to sell directly to affiliated buyers. The merchant mode is more profitable when the chicken-and-egg problem for the two-sided platform is more severe and when the degree of complementarity among sellers' products is higher. The platform mode is preferred when seller investment incentives are important or when there is asymmetric information regarding seller product quality. We discuss these tradeoffs in the context of several prominent digital intermediaries.
\end{abstract}

\section{Introduction}

With ever more sophisticated logistics and the rise of information technologies, intermediaries and market platforms have become increasingly ubiquitous and important agents in the digital economy. Sites such as Alibaba, Amazon, eBay, Google Video, imode $^{1}$, iTunes, Rakuten ${ }^{2}$, YouTube, etc. help connect tens of thousands of sellers to tens of millions of buyers. While market intermediation is not a new phenomenon, the digital economy has revealed that there can be two polar types of intermediaries: "merchants", who acquire goods ${ }^{3}$ from sellers and resell them to buyers, and "two-sided platforms", who allow "affiliated" sellers to sell directly to "affiliated" buyers.

This paper is a first pass at clarifying the differences between these two forms of market organization by intermediaries and the economic tradeoffs involved, which we show are more profound than the presence of absence of indirect network effects.

The main difference between the classic form of market intermediaries - which we will call merchants from now on - and two-sided platforms is that pure merchants, by taking possession of sellers' goods, take full control over their sale to consumers. By contrast, pure two-sided platforms leave that control entirely to sellers and simply determine buyer

\footnotetext{
* Harvard Business School, Morgan Hall \#212, Cambridge, MA 02163, USA. Email: ahagiu@hbs.edu I am grateful to two anonymous referees for improving this paper. All errors are mine.

${ }^{1}$ The world's most successful mobile Internet service, launched in 1999 by NTT DoCoMo, Japan's leading mobile operator. As of January 2007, i-mode connects more than 50 million users to 100,000 sites.

${ }^{2}$ Japan's largest online shopping mall, offering access to more than 18,000 merchants, selling more than 18 million products.

${ }^{3}$ This may either mean physical ownership or simply the right to sell (exclusive or not) for digital goods.
} 
and seller affiliation with a common marketplace. The following figure depicts this difference:
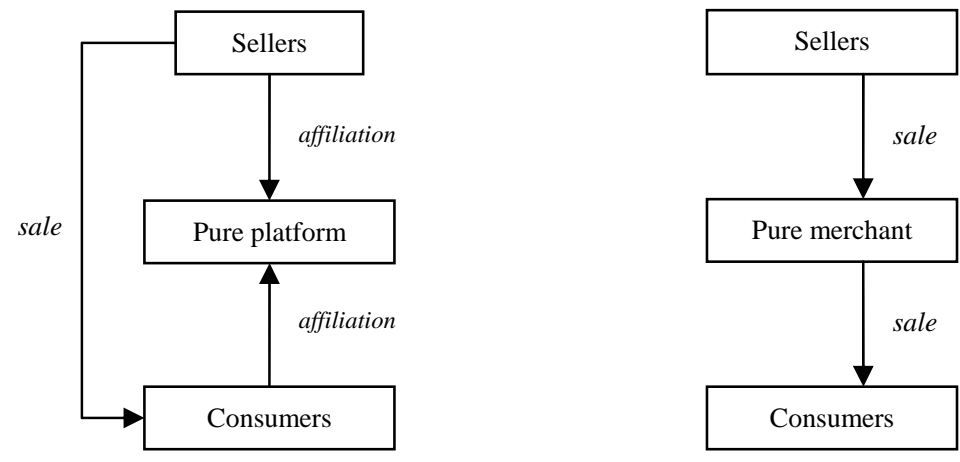

To give a few examples, retailers like Walmart and Amazon are (mostly) merchants. At the opposite end of the spectrum, eBay is a pure two-sided platform. More interesting are intermediaries, such as Apple's iTunes digital music store, which exhibit both platform and merchant features and therefore lie in-between these two extremes. Although Apple does not take physical or full legal "possession" of the songs it distributes (the rights remain with music publishers), it does obtain the right to repackage and price them as it sees fit on iTunes. The 99 cents per song policy is entirely Apple's unilateral decision (and is increasingly contested by music studios), designed to provide simplicity of usage to consumers and promote sales of Apple's associated digital music player, the iPod ${ }^{4}$. Thus, even though the combination iPod/iTunes exhibits two-sided indirect network effects (music publishers obtain higher profits by signing a distribution deal with Apple's iTunes when more consumers buy iPods, and vice versa), the extent of control over pricing and distribution that Apple maintains make iTunes more similar to a merchant such as Walmart, rather than a pure two-sided platform, such as eBay.

Using a simple framework, we formalize the economic tradeoffs between the pure (one-sided) merchant "mode" and the pure two-sided platform "mode". First, we show that, unlike the pure merchant mode, the pure two-sided platform mode exhibits indirect network externalities between sellers and consumers (buyers). As a consequence, sellers may be unwilling to affiliate with the platform because they anticipate other sellers will not do so, leading to low consumer demand for the platform, which ex-post justifies a nonaffiliation decision. In such cases, the merchant model helps "break" these unfavorable seller expectations by eliminating indirect network effects and achieves higher total profits. On the other hand, however, the merchant model may entail higher costs per seller inventory, risk, management, etc. - so that a platform model is more desirable when one wants to achieve higher product variety (and the risk that seller hold unfavorable expectations is not too high).

Second, the merchant mode also dominates the platform mode whenever there are significant complementarities and/or substitutability between sellers' products that sellers pricing independently (on a platform) do not internalize. By taking control over pricing (as well as advertising, distribution, bundling, etc.) decisions, the merchant can create more

\footnotetext{
${ }^{4}$ Indeed, Apple's profits from the iPod/iTunes combination come largely from sales of iPod, where the company enjoys margins higher than 20 percent. On the music side, it is estimated that Apple makes less than 10 cents for every song.
} 
value and extract more profits from consumers. In addition, we also show that a platform faces an inherent hold-up problem when contracting with sellers before selling to consumers, since it does not take into account seller profits when it sets its access price to consumers, therefore tends to excessively limit consumer adoption. By definition, a merchant fully internalizes seller profits ${ }^{5}$.

Third, whenever sellers can make quality enhancements to their products after contracting with the intermediary and before selling to consumers, the platform mode is more desirable since it preserves seller investment incentives by making them the residual claimants of those investments. Similarly, when quality is uncertain, the intermediary is better off devolving the corresponding risk at least partially back to the sellers, by using a platform mode.

\section{$1.1 \quad$ Related literature}

In distinguishing between the merchant and two-sided platform modes of market intermediation, this paper connects for the first time two previously separate strands of economics research. On the one hand, the literature on market microstructure and intermediation (Rubinstein and Wollinsky (1987), Stahl (1988), Biglaiser (1993), O’Hara (1995), Spulber (1996a) and (1996b), Rust and Hall (2001)) concerns itself with the merchant form of intermediation. The focus has been on understanding how intermediaries help homogeneous product markets clear by setting bid and ask prices to match supply with demand and by providing liquidity (O'Hara (1995)), as well as on deriving the welfare effects of the presence of intermediaries. Several papers have also studied the role of such intermediaries in quality certification and shown that they exhibit economies of scale when reducing adverse selection concerns (Biglaiser (1993)). Some papers also distinguish between marketmakers - which post publicly observable bid and ask prices and middlemen - whose bid and ask prices can only be discovered through costly search (Rust and Hall (2001)). However, all intermediaries studied in this literature are assumed to buy products from sellers and resell to buyers at the posted prices, subject to the constraint that demand does not outstrip supply for any intermediary at any point in time ${ }^{6}$. In addition, there are no meaningful affiliation decisions of buyers or sellers with intermediaries since each can only conduct one-shot spot transactions with an intermediary: buy or sell a unit of the product at the announced ask (respectively bid) price. Hence, there are never any indirect network effects between buyers and sellers. Also, given the focus on homogeneous product markets, the only relevant transaction variable is price and it is always determined by the intermediary.

On the other hand, the recent literature on two-sided markets has focused exclusively on pure two-sided platform intermediaries, emphasizing the indirect network effects which arise between the two sides of the market when the latter have to affiliate with the platforms in order to be able to transact with one another (Armstrong (2006), Caillaud and

\footnotetext{
${ }^{5}$ This is true in the simple framework we present in this paper because we assume away the existence of seller transactions with consumers outside of the intermediary. If such transactions existed (for example, through alternative sales channels or simply brand name), then even the merchant mode would leave certain externalities on seller profits uninternalized.

${ }^{6}$ This is mainly because the literature was focusing on brick-and-mortar intermediaries such as retailers or wholesalers channeling physical goods, or stock exchanges, where short positions cannot - usually - outstrip long positions for long. By contrast, in many of the digital markets we have in mind, such considerations are largely irrelevant: inventory is not an issue with digital goods.
} 
Jullien (2003), Evans (2003), Hagiu (2006a) and (2006b), Rochet and Tirole (2003) and (2006), Schmalensee (2002)). Virtually all of these papers focus on the pricing structure chosen by two-sided platforms in order to internalize (partially) network externalities. While this literature takes the existence of indirect network effects as given, we show that it crucially depends on the nature of contracts between the intermediary and sellers. With pure buy-out contracts (merchant mode), the externalities disappear entirely, since they are fully internalized by the intermediary. More importantly, we show that there is in fact a continuum of intermediary types between a pure merchant and a pure two-sided platform, depending on the extent of control over buyer-seller interactions left to sellers. "Control" can be thought of as encompassing three important dimensions: control over strategic variables (pricing, advertising, distribution, etc.); sharing of economic risk (is the risk borne by the sellers or by the intermediary?) and "ownership" of buyers (how salient are individual sellers' "brands" relative to the intermediary's "brand" when buyers make their affiliation decisions?). A pure two-sided platform leaves control to sellers, whereas a merchant takes over full control.

As a consequence, our framework suggests an implicit definition of "two-sidedness", relying on the division of control between sellers and intermediaries, rather than on the effects of the pricing structure chosen by the intermediary, as is the case with the definition proposed by Rochet and Tirole (2006). In contexts with platforms intermediating transactions between buyers and sellers, the Rochet-Tirole definition is overly inclusive with respect to ours: indeed, even the pricing structure chosen by a pure merchant (that is, its bid and ask prices) affects the total volume of transactions conducted. The key difference is that the Rochet-Tirole framework presumes a platform intermediating transactions between buyers and sellers without taking full control over buyer-seller transactions. Thus, there is a sense in which our framework augments the Rochet-Tirole definition by identifying a space in which the boundary between what is two-sided and what is not depends on a richer set of factors than indirect network externalities and pricing structure effects. It is worth emphasizing again that our framework implies that two-sidedness is not a $0-1$ notion: rather, there is a continuum of forms of intermediation. The position along this continuum can be thought of as a strategic decision for the intermediary, involving the tradeoffs that we explore in the rest of the paper.

The remainder of the paper is organized as follows. We present our basic model in section 2, then we proceed to use variations of this model in order to formalize the respective effects of indirect network externalities, product complementarities/substitutability and investment incentives on the tradeoff between merchants and two-sided platforms in sections 3,4 and 5. Section 6 uses the insights drawn from the formal analysis to discuss several real world examples. Section 7 concludes.

\section{Basic modeling framework}

There is one intermediary which makes it possible for $n$ identical sellers to deliver their products to consumers (buyers). The intermediary can choose between two ways of functioning: a merchant (one-sided) mode and a two-sided platform mode. Under the merchant mode, the intermediary buys sellers' products by offering a buyout bid $B^{S}$ for each seller and resells the goods to consumers for an individual price $p^{M}(n)$ that it chooses. In the two-sided platform mode, the intermediary charges each seller an "access" 
or "affiliation" fee $P^{S}$, in exchange for which sellers can sell their goods directly to the consumers affiliated with the intermediary for an individual price $p^{P}(n)$. The price $p^{P}(n)$ is determined by competition between $n$ sellers for the consumers affiliated with the twosided platform. We assume each seller is of measure 0 (that is, $n$ is a continuum), so that it does not take into account the effect of its price on overall user demand for the platform. We also implicitly assume unaffiliated sellers cannot sell their products to consumers (affiliated or unaffiliated). This last assumption rules out competition among intermediaries - this would introduce strategic effects, some of which are explored in Hagiu and Lee (2006). We also rule out direct sale by sellers to consumers. This possibility would introduce externalities exerted by the direct sales channel over the sales through the intermediary, which would complicate the analysis significantly. We leave this extension of our model for future research.

Regardless of the mode - platform or merchant - chosen by the intermediary, consumers have to obtain access to (affiliation with) the intermediary in order to be able to purchase the sellers' products: we denote by $P^{C}$ the consumer access fee charged by the intermediary. This assumption is made in order to keep the two modes of intermediation as similar as possible to each other and focus the comparison on other factors. There is no a priori reason why a pure two-sided platform should be in a better position to charge consumer access fees than a pure merchant, or vice versa. In many cases, this fee is equal to 0: for instance, Amazon does not charge users for browsing its website.

Consumers buy either from the intermediary itself if the latter chooses to function in a merchant mode, or directly from the sellers affiliated with the intermediary, if the latter chooses the two-sided platform mode.

Let $V(n)$ denote the gross utility each user derives from having access to $n$ products through the intermediary. We assume $V(n)$ is increasing and either linear or strictly concave in $n$. The implicit assumption is that each user will consume all products available. One could write a richer model, in which each user consumes only a subset of the products available, but our main insights remain unchanged. Denote then by $F($.) the cumulative distribution function of a horizontal differentiation parameter across the population of users - which can be interpreted as the distance to the intermediary in taste space or the opportunity cost of visiting the intermediary. Then the number of users which choose to affiliate with the intermediary when the price of each good is $p$ and the intermediary charges $P^{C}$ for consumer affiliation, is given by:

$$
N^{C}=F\left(V(n)-n p-P^{C}\right)
$$

Each seller incurs a fixed cost $f$ to develop his product for the intermediary and a fixed distribution cost $c$ when he makes his product available through a two-sided platform ${ }^{7}$. If, however, the intermediary is a merchant, the latter takes over the distribution costs. We assume that a merchant's fixed cost of distributing $n$ products is $C(n)$. If the merchant benefits from economies of scale, then $C(n)<n c$, whereas if each individual

\footnotetext{
$7 f$ and $c$ are the same for all sellers. The substance of our analysis would be unchanged if we allowed $f$ or $C$ to be distributed according to non-degenerate distributions.
} 
seller is more efficient at distributing its own product than the merchant, then we have $C(n)>n c$.

Thus, when selling through a merchant offering bid $B^{S}$, each seller makes total profits:

$$
\pi^{M}=B^{S}-f
$$

When selling through a platform, those profits are:

$$
\pi^{P}(n)=p^{P}(n) N^{C}-P^{S}-f-c=p^{P}(n) F\left(V(n)-n p^{P}(n)-P^{C}\right)-P^{S}-f-c
$$

Thus, the key difference in this very basic framework is that under the pure platform mode, sellers care about the number of consumers patronizing the intermediary, whereas under the pure merchant mode, they only care about the buyout bid.

The timing of the general pricing/adoption game we consider throughout the paper is:

1. The intermediary announces seller access fee $P^{S}$ or buyout offer $B^{S}$ (depending on the chosen mode) and $P^{C}$, the access price it will charge consumers in the third stage. ${ }^{8}$

2. Sellers decide whether or not to accept the intermediary's offer and those who do incur the cost $f$ to make their products available through that intermediary.

3. Consumers decide whether or not to affiliate with the intermediary.

4. Under the merchant mode, the intermediary chooses price $p^{M}(n)$ and under the platform mode, affiliated sellers choose price $p^{P}(n)$; in both cases, affiliated consumers decide whether or not to buy seller products.

Note that we implicitly assume that all bargaining power lies with the intermediary when it makes pricing or buyout offers to sellers, that is, it will always charge a price that makes sellers just indifferent between accepting or not ${ }^{9}$.

Finally, we take $n$ as exogenously given throughout the paper. While nothing would change in our simple framework if $n$ were endogenously chosen by the intermediary, it is important to note that in a richer model, with risk and uncertainty incorporated, the choice of $n$ may turn out to have significant implications.

\section{$3 \quad$ Indirect network externalities}

In this section, we assume for simplicity that $V($.$) is linear, that is, V(n)=v_{0}+n \times v$, and $p^{P}(n)=p$ exogenously given ${ }^{10}$, with $v>p>0$. In other words, sellers' products are identical but independent of one another.

\footnotetext{
${ }^{8}$ We assume that the intermediary can commit to $P^{C}$ in period 1 ) in order to abstract - for now - from a hold-up problem which arises when commitment is not possible (see section 5).

${ }^{9}$ Introducing variable degrees of bargaining power would simply make the difference between merchants and two-sided platforms less stark in this framework without changing the main insights.
} 


\section{a) Two-sided platform mode}

In this case, sellers' profits from affiliating with the platform are:

$$
\pi(n)=p F\left(v_{0}+n(v-p)-P^{C}\right)-P^{S}-f-c
$$

Clearly, there are indirect network externalities among sellers, which means that multiple equilibria exist. The following analysis relies on Hagiu (2006a) for the notions of favorable and unfavorable seller expectations and corresponding solution concepts.

If seller expectations are "favorable" to the platform, then every seller expects all other sellers to affiliate with (adopt) the platform whenever:

$$
p F\left(v_{0}+n(v-p)-P^{C}\right)-P^{S}-f-c \geq 0
$$

and in that case he will adopt the platform whenever this condition holds as well. It is easily seen that this is an equilibrium strategy for sellers given $P^{S}$ and $P^{C}$, therefore the platform can charge:

$$
P^{S}=p F\left(v_{0}+n(v-p)-P^{C}\right)-f-c
$$

This leads to total profits:

$$
P^{C} N^{C}+n P^{S}=\left(P^{C}+n p\right) F\left(v_{0}+n v-n p-P^{C}\right)-n(f+c)
$$

which the platform maximizes over $P^{C}$ to obtain:

$$
\Pi_{F}^{P}=\max _{P^{C}}\left\{P^{C} F\left(v_{0}+n v-n p-P^{C}\right)+n p F\left(v_{0}+n v-n p-P^{C}\right)\right\}-n(f+c)
$$

If expectations are "unfavorable", then every seller expects no other seller will affiliate with the platform unless ${ }^{11}$ :

$$
p F\left(v_{0}-P^{C}\right)-P^{S}-f-c \geq 0
$$

It is easily seen that adopting, if and only if, this condition holds, is also an equilibrium strategy for sellers sustained by unfavorable beliefs. In this case, the platform can only charge:

$$
P^{S}=p F\left(v_{0}-P^{C}\right)-f-c
$$

and attracts all sellers. Total platform profits are then:

$$
\Pi_{N F}^{P}=\max _{P^{C}}\left\{P^{C} F\left(v_{0}+v n-n p-P^{C}\right)+n p F\left(v_{0}-P^{C}\right)\right\}-n(f+c)
$$

\footnotetext{
${ }^{10}$ This could be the price of the products in an alternative, larger channel, or simply the monopoly price in a context with elastic and independent consumer demands for seller products.

${ }^{11}$ Recall that each individual seller is of measure 0.
} 
and clearly:

$$
\Pi_{N F}^{P}<\Pi_{F}^{P}
$$

\section{b) Merchant mode}

The intermediary behaves as a merchant in the sense that instead of trying to "attract" sellers, it simply buys their products and resells them to consumers. Given our assumption that the intermediary has all the bargaining power in both modes, a seller will accept the bid if and only if:

$$
B^{S} \geq f
$$

Therefore, in this case, there are no indirect externalities to speak of. Each seller only cares about the bid she is being offered, not about the number of consumers that the merchant will be able to attract. Nor does any seller care about what the other sellers do.

The optimal strategy for the merchant is then to set $B^{S}=f$ and merchant profits are simply:

$$
\begin{aligned}
\Pi^{M} & =\max _{P^{C}, p}\left\{\left(P^{C}+n p\right) F\left(v_{0}+n v-n p-P^{C}\right)\right\}-n f-C(n) \\
& =\Pi_{F}^{P}-[C(n)-n c]
\end{aligned}
$$

We have thus proven the following proposition:

Proposition 1 The merchant mode is strictly preferred to the two-sided platform mode when the probability of unfavorable seller expectations is high enough or when the economies of scale in distribution are sufficiently large.

The insight contained in this result is quite straightforward: it is easier (cheaper) to convince sellers to sell their products outright than to affiliate to a platform and sell the products to consumers themselves because the first option eliminates coordination issues.

On the other hand, however, a merchant generally incurs higher costs per seller, corresponding for instance to inventory and risk undertaken when taking possession of sellers' products, and to higher operational complexity (all products go through the merchant). Thus, the tradeoff between the merchant mode and the two-sided platform mode in this simple setting is between the higher operational costs of buying and selling products, and the higher costs of "convincing" sellers to affiliate. This suggests that intermediaries, especially for new goods, will generally start under a merchant format and, as a critical mass of sellers become affiliated, move towards a more "open”, platform mode, which allows intermediaries to offer a broader variety of products. If, on the other hand, there are persistent economies of scale associated with centralized distribution, then the merchant mode will be more appropriate for increasing product variety.

In order to focus on other factors driving a wedge between the relative profitabilities of the two modes of intermediation, we will assume away from now on all distribution costs ( $c=0 ; C(n)=0$ ), so that the only fixed costs are development costs. 


\section{$4 \quad$ Pricing distortions, product complementarity/substitutability}

Another factor which typically makes the merchant mode more desirable for the intermediary is the existence of pricing distortions.

The first type of pricing distortion is the one introduced by independent seller pricing in a two-sided platform mode. Indeed, whenever sellers' products are complementary (substitutable), by pricing independently, sellers fail to internalize complementarity (substitutability) effects, leading to too high (too low) prices (that is, $p^{P}(n) \gtrless p^{M}(n)$ ).

To see this, assume $P^{C}$ is exogenously fixed to $\bar{P}$ in both the merchant and the platform mode - this assumption helps us abstract from the hold-up issue analyzed below. In this case, under a two-sided platform mode, the intermediary sets:

leading to ${ }^{12}$ :

$$
P^{S}=p^{P}(n) F\left(V(n)-n p^{P}(n)-\bar{P}\right)-f
$$

$$
\Pi^{P}=\left[\bar{P}+n p^{P}(n)\right] F\left(V(n)-n p^{P}(n)-\bar{P}\right)-n f
$$

whereas under the merchant mode:

$$
\Pi^{M}=\max _{p}\{\{\bar{P}+n p] F(V(n)-n p-\bar{P})\}-n f
$$

Clearly, $\Pi^{M}>\Pi^{P}$ because the merchant has the flexibility to internalize the complementarity (subtitutability) between seller products.

Note that if $\bar{P}$ were not exogenously given and could be chosen freely by the intermediary, then the two modes lead to the same level of profits. The additional degree of freedom that the merchant possesses in choosing $p$ is not necessary for reaching the first best level of profits in this simple model. Of course, in reality, that additional degree of freedom can make a big difference, as soon as the interval in which $P^{C}$ can vary is limited (for example, Internet digital music stores usually cannot charge access fees to users) or consumers are vertically differentiated so that using a razor-and-blades pricing strategy is optimal. This is especially true when there are other variables that the merchant can choose (advertising levels, bundling strategies, store layout and design, etc.), which can create value above and beyond what the sellers can create by acting independently. Again, the tradeoff is that the merchant mode may incur higher operational costs than the platform mode.

The second type of price distortion is the one which arises when the platform cannot credibly commit to $P^{C}$ in the first stage, upon contracting with sellers. In this case, the timing changes to:

(1) The intermediary announces seller access fee $P^{S}$ or buyout offer $B^{S}$ (depending on the chosen mode).

\footnotetext{
${ }^{12}$ From now on, we assume away the possibility of unfavorable seller expectations and focus on favorable expectations.
} 
(2) Sellers decide whether or not to accept the intermediary's offer and those who do incur the cost $f$ to make their products available through that intermediary.

(3) The intermediary sets the access price $P^{C}$ for consumers and the latter decide whether or not to affiliate with the intermediary.

(4) Under the merchant mode, the intermediary chooses price $p^{M}(n)$ and under the platform mode, affiliated sellers choose price $p^{P}(n)$; in both cases, affiliated consumers decide whether or not to buy seller products.

As shown in Hagiu (2006b), a hold-up problem arises between the platform and sellers. Indeed, in the third stage, the platform sets:

$$
P_{2}^{C *}=\arg \max _{P^{C}} P^{C} F\left(V(n)-n p^{P}(n)-P^{C}\right)
$$

which fails to take into account seller profits $n p^{P}(n) F\left(V(n)-n p^{P}(n)-P^{C}\right)$. As a result, $P^{C}$ will be set too high relative to the price which maximizes joint profits, that is:

$$
P_{2}^{C *}>P^{C *}=\arg \max _{P^{C}}\left(P^{C}+n p^{P}(n)\right) F\left(V(n)-n p^{P}(n)-P^{C}\right)
$$

This is ex-ante reflected in $P^{S}$ : the platform has to lower the affiliation fee for sellers in order to compensate them for the platform's subsequent failure to internalize their profits:

$$
P^{S}+f=p^{P}(n) F\left(V(n)-n p^{P}(n)-P_{2}^{C *}\right)<p^{P}(n) F\left(V(n)-n p^{P}(n)-P^{C *}\right)
$$

By contrast, the merchant mode allows the intermediary to fully internalize seller profits (it buys them out!) from the third stage on:

$$
\Pi_{2}^{M}=\max _{P^{C}, p}\left(P^{C}+n p\right) F\left(V(n)-n p-P^{C}\right)
$$

yielding total merchant profits from the perspective of stage 1 :

$$
\Pi^{M}=\left(P^{C *}+n p^{P}(n)\right) F\left(V(n)-n p^{P}(n)-P^{C *}\right)-n f
$$

For example, with linear consumer demand $F(u)=u$, we obtain:

$$
\Pi^{P}=\frac{1}{4}\left[(V(n))^{2}-\left(n p^{P}(n)\right)^{2}\right]-n f<\Pi^{M}=\frac{1}{4}(V(n))^{2}-n f
$$

Thus, the merchant mode does strictly better than the platform mode, even in the absence of seller coordination problems.

One could argue that an easy way for the platform to get around this hold-up problem is to charge sellers variable fees (or royalties), which is often the case with real-world 
intermediaries. Indeed, assume now that under the two-sided platform mode, the intermediary can charge both the fixed fee $P^{S}$ and a royalty $\rho$, proportional to the price $p^{P}(n)$ charged by sellers to consumers, $0 \leq \rho \leq 1$. In the second stage, the platform sets:

$$
P^{C^{*}}(\rho)=\arg \max _{P^{C}}\left[P^{C}+n \rho p^{P}(n)\right] F\left(V(n)-n p^{P}(n)-P^{C}\right)
$$

And in the first stage, the platform can therefore charge:

$$
P^{S}=(1-\rho) p^{P}(n) F\left(V(n)-n p^{P}(n)-P^{C *}(\rho)\right)-f
$$

leading to total platform profits:

$$
\Pi^{P}=\max _{\rho}\left[P^{C *}(\rho)+n p^{P}(n)\right] F\left(V(n)-n p^{P}(n)-P^{C *}(\rho)\right)-n f
$$

It is then easily seen that setting $\rho=1$ achieves the first-best level of profits, so that:

$$
\Pi^{P}(\rho=1)=\Pi^{M}
$$

But $\rho=1$ simply means that the platform is the residual claimant of all second-stage seller revenues (from selling to consumers), which is equivalent for all practical purposes to a merchant mode, that is, the intermediary taking possession of sellers' products).

It goes without saying that in reality, it is rarely feasible to charge $\rho=1$, that is, to extract all revenues from sellers. There are several important reasons for this: the need to preserve seller investment incentives (when the latter need to invest in enhancing the quality of their products after having contracted with the platform) and asymmetric information about product quality, which requires the sellers to bear at least some of the risk associated with their products ( $\rho=1$ transfers all the risk to the platformintermediary).

\section{$5 \quad$ Hold-up vs. preserving innovation incentives}

In the previous sections, we have seen that seller coordination issues notwithstanding, there are generally good reasons for the intermediary to function as a merchant in order to internalize product complementarities. If there were no countervailing forces to shift the balance in favor of the two-sided platform mode, one would observe many more merchanttype intermediaries.

Two such countervailing forces are asymmetric information and the need to preserve seller incentives to invest in product quality. On the first point, it is sufficient to point out that even though eBay may be able to extract higher payments from users by bundling and pricing together some of the products offered by its sellers, it would simply not be reasonable to buy all of these products, given the little information it has about them and their sellers. 
The second point is related but less straightforward. It is useful to think of the example of videogames here: why don't manufacturers of consoles function as pure merchants for all the games sold on their platforms? The problem is that the contractual arrangements with game developers occur long before the console and the games are finished. If the console maker was to agree to buy out a game developer at this stage, the latter would no longer have any incentives to continue working on improving his game. A better arrangement may then be for the console maker to allow the developer to be the residual claimant of the revenues derived from the game and perhaps extract some royalty payments in order to deal with its own incentives to expand the user market for consoles. We formalize this tradeoff in what follows.

Assume that the quality of seller products is variable. The variant of the model that we use here draws upon Hagiu (2006b). Under the platform mode, each seller can produce a product of quality $q$ at fixed cost $f=\frac{c q^{2}}{2}$. If the intermediary opts for the merchant mode and takes possession of seller products, it can invest itself in improving product quality, at a cost $\frac{C q^{2}}{2}$.

The timing of the game is now slightly different to reflect investments in product quality:

(1) The intermediary contracts with sellers (announces $P^{S}$ or $B^{S}$ ).

(2) The sellers or the intermediary (depending on who owns the products at this stage) invest in product quality.

(3) The intermediary sets the access price $P^{C}$ to consumers.

(4) Sellers or the intermediary sell products to consumers.

By symmetry, all sellers' products will be of the same quality, regardless of the mode chosen by the intermediary. We assume that when the common quality is $q$, consumer gross surplus from the $n$ goods is $V(n q)$, where $V($.$) is increasing and concave. This$ implies that $p^{P}(n, q)=q V^{\prime}(n q)$. In what follows, we will use $V(x)=A x^{\beta}, 0 \leq \beta<\frac{1}{2}$. Finally, we also assume consumers' demand for affiliation with the platform/merchant is linear: $F(u)=u$.

The following proposition contains the key result of this section.

Proposition 2 The total profits obtained under a platform mode, $\Pi^{P}$, are higher than the total profits obtained under a merchant mode, $\Pi^{M}$, if and only if:

$$
(1-\beta)(1+\beta)^{\frac{1+\beta}{1-\beta}}\left(\frac{C}{C}\right)^{\frac{\beta}{1-\beta}}<1
$$

Proof See appendix. 
First, note that when $C \leq c$, that is, the merchant is at least as efficient in investing in product quality as the sellers themselves ${ }^{13}$, then the merchant mode is always preferred since $(1-\beta)(1+\beta)^{\frac{1+\beta}{1-\beta}}>1$ for all $\beta>0$. This is simply because the merchant mode avoids the hold-up problem while still providing the optimal quality level.

If on the other hand $C$ is sufficiently high relative to $c$, then the platform mode is preferred by the intermediary. Indeed, in that case, the gains from devolving control over and providing incentives for quality investments to sellers outweigh the drawback of incurring the hold-up problem.

It should be clear that all of the above results hold when $n$ is not exogenously given, but chosen by the intermediary implicitly through its choice of $P^{S}$.

\section{Discussion}

The formal analysis in the previous three sections makes it clear that the tradeoff between the merchant mode of intermediation and the two-sided platform mode runs far deeper than the presence of indirect network externalities or absence thereof. In order to get a sense of how the distinction between the two modes works in real-world examples, we offer two representative mini-case studies in this section.

\subsection{Amazon}

Amazon, the world's leading online retailer, has undertaken a clear transition from a pure merchant to a two-sided platform-like intermediary over its 12-year history. When Jeff Bezos started the company in 1995, it was very close to a pure merchant mode, with the exception of certain contractual arrangements designed to transfer some inventory risk back to book wholesalers. After developing a sophisticated e-commerce and database infrastructure, Amazon started its "marketplace" initiative in 1999. Under this initiative, the company began allowing some of its suppliers ${ }^{14}$ to operate their own storefronts on the Amazon.com website. Today, its contractual relationships with merchants fall roughly into 5 categories: zShops for small merchants, Merchants@Amazon.com, Merchants.com, syndicated stores and marketing deals, the last four targeting large business sellers. These new ways of contracting with suppliers represented a significant change in the way Amazon perceived its intermediation business. As explained by Jeff Bezos:

"One of the things we had to learn through zShops and auctions was that we needed to think of ourselves as serving two distinct sets of customers. We pride ourselves in being "customer-centric", but for years “customers” meant "buyers”. As we began to operate auctions and zShops we realized that these third-party sellers were equally important customers. And it took a little while for the organization to learn what their needs were and how we could best serve them." (Leschly et al (2002), p.7)

\footnotetext{
13 Again, this may be because the merchant benefits from economies of scale in accumulating some knowhow over and above what each individual seller can achieve by himself.

${ }^{14}$ Amazon refers to its suppliers as "merchants", but in order to maintain consistency and avoid confusion, we will call them "suppliers".
} 
The five contractual relationships described above differ in the share of inventory risk and control Amazon is taking on. For instance, under the Merchants@Amazon.com arrangement, suppliers can sell products through Amazon's website while still performing many of the commerce functions themselves, such as maintaining ownership of and setting prices on inventory. By contrast, under the Merchants.com arrangement, Amazon operates third-party supplier websites (for example, www.Target.com) but takes inventory in its distribution centers and completes order fulfillment functions itself. In both cases, Amazon charges a fixed fee and a commission per item sold, ranging from 5\% (when Amazon does not take significant inventory functions and risks) to 15\% (when it does).

It is interesting to note a straightforward parallel between the third-party, digital storefronts on Amazon.com in the online world and the Wal-Mart's practice of renting out shelf space to some of its suppliers in the brick and mortar world. Indeed, instead of buying all products and reselling them, thus effectively taking ownership, Wal-Mart rents shelf-space to some suppliers such as Kellogg and Coca-Cola. These suppliers are responsible for stocking, displaying, pricing and advertising their merchandise, within the space allocated by Wal-Mart. The efficiency gains come from providing suppliers with incentives to use price, advertising, and display to maximize profits, part of which WalMart can extract through higher rents. On the other hand, some efficiency is lost because suppliers do not fully internalize the effects of their in-store actions on other suppliers (see section 4). Kellogg, Coke and others are more than a little interested in the traffic WalMart generates, since this determines how many consumers are likely to stop by their stands and eventually buy their products. It makes sense to think of them as "on board" the Wal-Mart two-sided platform.

\subsection{Digital music and videos}

We now turn to intermediaries of digital goods, for which inventory risk becomes irrelevant. In this context, the only thing that matters for the distinction between merchants and two-sided platforms is the allocation of control rights - between sellers and the intermediary - over strategic variables such as pricing, display, bundling, etc.

As pointed out in the introduction, although at first glance the iTunes digital music store looks like a two-sided platform, Apple's almost absolute control over music and movie pricing (\$0.99 per song, \$1.99 per TV series episode, \$9.99 and \$14.99 per movie downloaded), as well as over the consumer interface, makes it quite merchant-like. Apple's contention is that having a unified, easy-to-use interface, as well as a very simple pricing scheme, are critical to attracting consumers to the iTunes store, and that these attributes may be lost under a more decentralized control structure.

It is instructive to compare the respective modes of distribution of music content and of videogame content. Even at the very beginning of a new console generation, videogames are rarely sold under a merchant mode by the console manufacturers, with the exception of the few titles that every console buys out in order to ensure their exclusivity and solve the initial "chicken-and-egg" problem (consistent with our section 3 above). The reason has less to do with product variety (consumer demand for variety is arguably equally high in both markets) than with the significant asymmetry of information and need to preserve developer incentives to invest resources in enhancing game quality in the videogame case. By contrast, at the time music labels contract with digital distributors such as Apple's iTunes or Real Networks' Rhapsody, the "quality" of the songs (that is, their popularity) is usually known, therefore the intermediary mode chosen is determined by other 
considerations, such as the ability of a merchant to extract higher profits from consumers through creative pricing and bundling schemes.

An approach similar to Apple's in digital music has been adopted by many of the leading Internet video portals - currently the fastest growing online sector. Google Video/YouTube ${ }^{15}$ is a case in point. Here, it is important to first distinguish between consumer generated media (CGM) and professional and semi-professional video content, produced by content publishers. The former constitute the majority of videos watched online today, however, the latter are growing faster and most industry experts agree that this is where the most interesting revenues potential lies. CGM is entirely free, therefore, largely irrelevant to our discussion. For professional content, Google/YouTube restricts providers to charging $\$ 1.99$ or $\$ 3.99$.

However, some competitors, such as Brightcove.com, have already opted to differentiate themselves from Google through the flexibility they offer content providers in choosing their revenue models - pay-per-view, pay-per-download or advertisingsupported. In addition, Brightcove even allows its content providers to have store fronts on its website from which users can "jump" directly to the content providers' websites. Brightcove's vision is thus to "own" users by maintaining user accounts and placing itself at the nexus of the exploding market for Internet videos, without attempting to exert too much control over the transactions themselves.

It is interesting to ask what needs to happen in order for the pure two-sided platform strategy to become dominant for all of these sites. Presumably, over time, consumers will become more accustomed to such services, so that there will be less value created by uniform and centralized pricing.

The key insight which emerges from the preceding discussion and formal analysis is that the distinction between the two modes of intermediation - merchant vs. two-sided platform - is contractual. Where a given intermediary is located along the merchantplatform continuum depends on the allocation of control rights over the decision variables impacting the sale of products to consumers, on the sharing of economic risk and on the allocation of consumer ownership between suppliers and the intermediary.

\section{Conclusion}

In this paper, we have shown that the tradeoff between the merchant form of intermediary organization and the two-sided platform form is affected by several fundamental economic factors: indirect network effects between buyers and sellers; asymmetric information between sellers and the intermediary; investment incentives and product complementarities/substitutability. The following table summarizes all of the relevant factors and their effects on the desirability of each of the two modes of intermediary organization.

\begin{tabular}{|l|c|c|}
\hline Economic issue & Platform mode & Merchant mode \\
\hline Unfavorable expectations by sellers & - & + \\
\hline Asymmetric information (sellers) & + & - \\
\hline
\end{tabular}

15 Google famously acquired YouTube in October 2006 for \$1.6 billion, but for now, the two portals continue to co-exist side by side. 


\begin{tabular}{|l|c|c|}
\hline $\begin{array}{l}\text { Strong complementarity or substitutability } \\
\text { between sellers' products }\end{array}$ & - & + \\
\hline Need for ongoing investments by sellers & + & - \\
\hline $\begin{array}{l}\text { Need for ongoing investments by the } \\
\text { intermediary }\end{array}$ & - & - \\
\hline Uncertainty (consumer demand) & + & - \\
\hline Consumer demand for product variety & - & + \\
\hline Consumers unfamiliar with seller products wignificant "contact" with \\
\hline $\begin{array}{l}\text { Suppliers have signediary (for } \\
\text { consumers outside the intermediame, } \\
\text { example, brand name) }\end{array}$
\end{tabular}

Table 1: Platform mode vs. merchant mode

Note that this table and the analysis above hold true for a monopoly intermediary. With competing intermediaries, more subtle strategic issues may arise which are beyond the scope of this paper. For example, Hagiu and Lee (2006) study the strategic effects of intermediaries devolving control over content pricing to content providers, in a context with intermediaries competing for content and consumers.

Clearly, this paper is only a preliminary treatment of the economic tradeoffs enumerated above. The main contributions have been to establish a connection between the recent literature on two-sided markets and the one on market intermediaries and to identify the factors driving the choice between the two polar forms of market organization for intermediaries. This should provide the initial starting point for future economics research on this topic.

\section{$8 \quad$ References}

Baumol, W. and J. Sidak (1994) "The Pricing of Inputs Sold To Competitors," Yale Journal on Regulation, 11: 171-202.

Armstrong, M. (2006) “Competition in Two-Sided Markets,” Rand Journal of Economics, 37: 668-691.

Biglaiser, G. (1993) “Middlemen as Experts,” Rand Journal of Economics, 24: 212-223.

Caillaud, B., and B. Jullien (2003) "Chicken and Egg: Competition Among Intermediation Service Providers,” Rand Journal of Economics, 34: 309-328.

Evans, D. S. (2003) “The Antitrust Economics of Multi-Sided Platform Markets," Yale Journal on Regulation, 20: 325-82.

Evans, D. S., A. Hagiu and R. Schmalensee (2006) "Invisible Engines: How Software Platforms Drive Innovation and Transform Industries,” MIT Press, October.

Hagiu, A. (2006a) "Pricing and Commitment by Two-Sided Platforms," Rand Journal of Economics, 37: 2006. 
Hagiu, A. (2006b) “Two-Sided Platforms: Pricing, Product Variety and Social Efficiency,” mimeo, Harvard Business School.

Hagiu, A. and R. S. Lee (2006) "Exclusivity and Control," mimeo, Harvard Business School.

Hagiu, A and D. B. Yoffie (2006) "Brightcove and the Future of Internet Television," Harvard Business School Case N9-707-457.

Leschly, S., M. J. Roberts, W. A. Sahlman (2003) “Amazon - 2002,” Harvard Business School case 9-803-098

O’Hara, Maureen (1995) Market Microstructure Theory. Blackwell: Oxford.

Rochet, J.-C., and J. Tirole (2003) "Platform Competition in Two-Sided Markets,” Journal of the European Economic Association, 1: 990-1029.

Rochet, J.-C., and J. Tirole (2004) “Two-Sided Markets: Where We Stand,” Rand Journal of Economics, 37: 2006.

Rubinstein, A. and A. Wolinsky (1987) “Middlemen,” Quarterly Journal of Economics, 102: 581-593.

Rust, J. and G. Hall (2003), "Middlemen vs. Market Makers: A Theory of Competitive Exchange,” Journal of Political Economy, 111: 2003.

Schmalensee, R. (2002) "Payment Systems and Interchange Fees," Journal of Industrial Economics, 50: 103-122.

Spulber, D. F. (1996) "Market Making by Price-Setting Firms," Review of Economic Studies, 63: 559-580.

Spulber, D. F. (1996) “Market Microstructure and Intermediation,” Journal of Economic Perspectives, 10: 135-152.

Stahl, B. (1988) "Bertrand Competition for Inputs and Walrasian Outcomes," The American Economic Review, 78: 189-201.

Yoffie, D. B. (2005) “Walmart, 2005,” Harvard Business School Case 9-705-460.

\section{$9 \quad$ Appendix}

Proof of proposition 2 Under the merchant mode, the intermediary can buy the goods at cost $f$ in the first stage, invest in quality $q$ and the sell them to consumers. In the second stage, it makes total profits:

$$
\max _{P^{C}}\left\{\left(P^{C}+n q V^{\prime}(n q)\right)\left(V(n q)-n q V^{\prime}(n q)-P^{C}\right)\right\}=\frac{(V(n q))^{2}}{4}
$$


Therefore, total merchant profits from the perspective of stage 1 are:

$$
\max _{q}\left\{\frac{(V(n q))^{2}}{4}-n \frac{C q^{2}}{2}-n f\right\}=\max _{q}\left\{\frac{A^{2} n^{2 \beta} q^{2 \beta}}{4}-n \frac{C q^{2}}{2}-n f\right\}
$$

leading to $q^{M}=\left[\frac{\beta A^{2}}{2 C}\right]^{\frac{1}{2-2 \beta}} n^{\frac{2 \beta-1}{2-2 \beta}}$ and:

$$
\Pi^{M}=(1-\beta) \frac{A^{2}}{4}\left[\frac{\beta A^{2}}{2 C}\right]^{\frac{\beta}{1-\beta}} n^{\frac{\beta}{1-\beta}}-n f
$$

A two-sided platform sets $P^{S}$ and $\rho$ in the first stage, which determine the quality $q$ chosen by sellers in the second stage, anticipating the price $P^{C}$ that the platform will charge consumers in the third stage. Third stage platform profits are:

$$
\max _{P^{C}}\left(P^{C}+\rho n q V^{\prime}(n q)\right)\left(V(n q)-n q V^{\prime}(n q)-P^{C}\right)=\frac{1}{4}\left[V(n q)-(1-\rho) n q V^{\prime}(n q)\right]^{2}
$$

and consumer adoption of the platform is:

$$
N^{C}=\frac{V(n q)-(1-\rho) n q V^{\prime}(n q)}{2}
$$

In the second stage, all sellers choose the same quality $q$ (by symmetry), given by ${ }^{16}$ :

$$
(1-\rho) V^{\prime}(n q) N^{U}=c q
$$

or:

$$
(1-\rho) V^{\prime}(n q) \frac{V(n q)-(1-\rho) n q V^{\prime}(n q)}{2}=c q
$$

Using $V(n q)=A(n q)^{\beta}$, we obtain $q^{P}(\rho)=\left[\frac{A^{2} \lambda(1-\lambda)}{2 c}\right]^{\frac{1}{2-2 \beta}} n^{\frac{2 \beta-1}{2-2 \beta}}$, where $\lambda=\beta(1-\rho)$. The platform can then charge:

$$
P^{S}=(1-\rho) q^{P} V^{\prime}\left(n q^{P}\right) \frac{V\left(n q^{P}\right)-(1-\rho) n q^{P} V^{\prime}\left(n q^{P}\right)}{2}-\frac{c\left(q^{P}\right)^{2}}{2}-f
$$

This leads to the following expression of platform profits:

\footnotetext{
${ }^{16}$ Recall our assumption that sellers are small enough so that they ignore the effects of their price and quality investments on total consumer demand for the platform.
} 


$$
\begin{aligned}
\Pi^{P} & =n P^{S}+\frac{1}{4}\left[V\left(n q^{P}\right)-(1-\rho) n q^{P} V^{\prime}\left(n q^{P}\right)\right]^{2} \\
& =\frac{1}{4}\left[\left(V\left(n q^{P}\right)\right)^{2}-\left((1-\rho) n q^{P} V^{\prime}\left(n q^{P}\right)\right)^{2}\right]-n \frac{c\left(q^{P}\right)^{2}}{2}-n f
\end{aligned}
$$

Plugging in the expression of $q^{P}(\rho)$ above, straightforward calculations yield:

$$
\Pi^{P}(\rho)=\lambda^{\frac{\beta}{1-\beta}}(1-\lambda) \frac{1}{1-\beta} \frac{A^{2}}{4}\left(\frac{A^{2}}{2 c}\right)^{\frac{\beta}{1-\beta}} n^{\frac{\beta}{1-\beta}}-n f
$$

Optimizing over $\lambda$ (implicitly over $\rho$ ), we obtain the optimal royalty rate chosen by the two-sided platform:

$$
\rho^{*}=\frac{\beta}{1+\beta}
$$

Clearly, $0<\rho^{*}<1$. The optimal royalty rate for the platform trades off the need to provide sufficient investment incentives to sellers (which requires low $\rho$ ) against the need to overcome the hold-up problem induced by third-stage pricing (which requires high $\rho$ ).

Total platform profits are then:

$$
\Pi^{P}=\frac{\beta^{\frac{\beta}{1-\beta}}}{(1+\beta)^{\frac{1+\beta}{1-\beta}}} \frac{A^{2}}{4}\left[\frac{A^{2}}{2 c}\right]^{\frac{\beta}{1-\beta}} n^{\frac{\beta}{1-\beta}}-n f
$$

Comparing the expressions of profits under the two different modes (2) and (3), we have $\Pi^{P}>\Pi^{M}$ if and only if condition (1) holds. 